\title{
Crowd Logistics Delivery Determinants: A Stated-Preference Survey
}

\author{
Ali Al-Saudi \\ aalsaudi@mail.hbku.edu.qa \\ Hamad Bin Khalifa University, College of Science and Engineering, Department of Logistics and Supply \\ Chain, Doha, Qatar \\ Frank Himpel \\ fhimpel@hbku.edu.qa \\ Hamad Bin Khalifa University, College of Science and Engineering, Department of Logistics and Supply \\ Chain, Doha, Qatar
}

\begin{abstract}
Crowd logistics (CL) has the potential to reduce the cost of last-mile delivery and benefit the environment. Consumers' attitudes toward CL are understudied, especially in Qatar, where CL is currently unavailable. The purpose of this paper is to investigate consumers' reactions to the theoretical attributes of a crowd-sourced delivery smartphone application along with customers' willingness to pay for particular features. A stated preference survey was distributed to potential consumers in Qatar and analyzed using a multinomial logit model. Package insurance was identified as the most important attribute, followed by a flexible delivery place and time with GPS tracking and a transparent delivery person profile. Respondents did not want their packages to be delayed by 30 minutes but did not mind a 15-minute delay. This model suggests that consumers are willing to pay up to $13.8 \mathrm{QR}$ for package insurance, implying a lack of trust in CL. This research offers valuable insights for businesses (e.g., to help them design relevant platforms) and policymakers (e.g., to potentially mitigate consumers' trust concerns around using occasional people for delivery). This study also helps fill a gap in CL behavioral studies and confirms extant research findings relative to customers' trust in CL.
\end{abstract}

Keywords: Logistics; Crowd-sourced; Delivery; Choice; Mlogit

\section{INTRODUCTION}

An increase in e-commerce has accompanied a growth in freight transport (Frehe et al., 2017). Of all logistics-related activities, transportation is believed to have the most negative impact on the environment (Edwards et al., 2010). In addition to its effects on sustainability, last-mile delivery is the most cost-intensive stage of transportation; it can contribute up to $28 \%$ of transportation costs (Odongo, 2018). The high cost and inefficiency of last-mile delivery is attributable to high consumer expectations regarding service quality (Savelsbergh \& Van Woensel, 2016). Notably, the last-mile issue is not limited to freight transportation; it applies to the private and public sectors as well (Zellner et al., 2016).

Several companies have sought to address this challenge without compromising service quality; for example, Amazon and Google are testing a same-day delivery service with drones (Brunner et al., 2018). Researchers have also begun to examine routing problems to optimize the delivery process (Savelsbergh \& Van Woensel, 2016). The use of electric vehicles or bikes, which have lower emissions than freight vehicles, has also 
been found to mitigate adverse environmental effects (Edwards et al., 2010).

Another growing trend related to e-commerce is crowd logistics (CL). This concept has been defined in various ways but generally refers to companies hiring everyday people to assume certain delivery tasks (Odongo, 2018). A more detailed overview of $\mathrm{CL}$ is provided in the literature review. Uber is a successful model of CL use (Carbone et al., 2017a). More companies have begun to follow the same business model for passenger transport and for general local delivery, such as DoorDash in the United States, PiggyBee in Europe, and many others (Carbone et al., 2017a). These companies serve as mediators; their primary asset is based on information and communications technology (ICT). Companies' platforms often rely on GPS-enabled devices such as smartphones (Frehe et al., 2017). These platforms must satisfy customers' evolving needs (in this case, consumers are service recipients) (Luisa Dos Santos Vieira et al., 2013). Therefore, it is important to explore these consumers' preferences to provide effective services.

Scholars who have systematically analyzed CL have identified a paucity of acceptance studies (Carbone et al., 2017a). Crowd (i.e., service recipient) behavior relative to $\mathrm{CL}$ is thus considered in this paper. Specifically, our research focuses on relationship-influencing factors to clarify CL acceptability and dispersal (Frehe et al., 2017). Despite the lack of literature in this field overall, many studies have addressed CL acceptance, mostly in Europe. However, scarce literature has examined CL acceptance in the Middle East. This paper aims to fill this gap by conducting a stated preference survey on factors affecting potential CL acceptability in Qatar. A given country's jurisdiction can influence CL practices; in the United States, for instance, crowd shippers are subject to labor regulations (e.g., minimum wage and maximum work time) (Castillo et al., 2018). In Qatar, where the survey in this study was conducted, certain stipulations apply. For example, to be an Uber driver, the driver must be employed by a taxi company that is registered in Qatar (Uber, 2019). This parameter violates CL principles, namely the use of occasional (unprofessional) people.

Our study makes two contributions to the literature: (1) we evaluate determining factors of CL use based on potential customers' feedback; and (2) we test customers' choice preferences of the identified determinants. The following literature review presents several influencing factors that were incorporated when designing stated preference attributes and levels for the survey in this study. Our findings should help future investors and stakeholders make decisions regarding the jurisdiction of CL acceptance, particularly in Qatar.

The remainder of this paper is organized as follows. Section 2 presents the literature review. The chosen survey methodology and corresponding data analysis are outlined in Section 3. Results are reported in Section 4, and Section 5 details our conclusions and future work.

\section{LITERATURE REVIEW}

The term crowd logistics combines two terms, logistics and crowdsourcing. The latter term integrates crowd and outsourcing (Peiling \& Tingting, 2018), in which 'crowd' encompasses a mass of people and 'outsourcing' refers to shifting processes and functions to a third party. The elements of crowdsourcing are as follows: (a) an organization has a pending task; (b) people (i.e., a crowd) are willing to undertake that task; (c) an 
online platform is available to facilitate interaction between the organization and crowd members; and (d) both parties receive mutual benefits from this task completion process (Brabham, 2013).

In this paper, we define $\mathrm{CL}$ as the outsourcing of logistics services to a crowd via a technological platform to realize economic benefits for all parties (Carbone et al., 2017a). $\mathrm{CL}$ is an aspect of the sharing economy, referring to the efficient use of physical assets supported by ICT (Buldeo Rai et al., 2017). CL has been widely discussed within the business domain; however, it has rarely been the subject of academic research (Carbone et al., 2017b). Most studies have explored the topic relative to business models, with comparatively little attention given to CL users' behavior and perceptions (Punel et al., 2018). Scholars have also investigated existing businesses by interviewing professionals (Frehe et al., 2017). Case studies are another means of assessing this phenomenon, especially in terms of identifying research areas and developing corresponding theories (Voss et al., 2002). Overall, however, few systematic studies have considered behavior around shared resources delivery (Stathopoulos \& Punel, 2016).

CL allows for greater customization for the customer (Punel \& Stathopoulos, 2017), which has been identified as an important factor in customer satisfaction (Ghajargar et al., 2016). For instance, CL firms can offer more affordable pricing compared to traditional shipping couriers (Rougès \& Montreuil, 2014) by optimizing resources without increasing infrastructure. CL also has the potential to benefit the environment by reducing the number of trips needed (assuming drivers are already travelling before assigning a job to them) and therefore congestion (Akyelken, 2011).

Crowd shippers are often non-professional drivers (Goetting \& Handover, 2016); as such, trust and privacy present obstacles for CL users (Rougès \& Montreuil, 2014). Service quality is another challenge because the drivers are occasional (Furuhata et al., 2013). Customers' expectations around service quality are also increasing, such as sameday delivery, package tracking, and overall satisfaction (Stathopoulos \& Punel, 2016). These demands may further complicate CL acceptance.

Because CL firms act only as mediators, it is important to study crowd user behavior (Frehe et al., 2017). As noted earlier, scholarship on the acceptability of CL is lacking (Punel \& Stathopoulos, 2017). Le and Ukkusuri (2019) studied individuals' willingness to work as crowd shippers using a binary logit model to estimate participants' discrete choices based on 549 survey responses. Ultimately, $78 \%$ of respondents reported being willing to work. Punel et al. (2018) used a binary logit model to distinguish preferences among users and non-users of CL, surveying 800 people in several U.S. states. They concluded that young men with full-time jobs were most accepting of CL. Punel et al. (2018) also found that "people with affordability and trust concerns were less likely than others to use CL". Le and Ukkusuri (2018) examined CL by distributing a stated preference survey in the United States and Vietnam. Their findings highlighted package condition and on-time delivery are the two most important attributes: $85 \%$ of respondents across the two countries expressed a preference for package insurance, and $67 \%$ and $46 \%$ preferred on-time delivery in the United States and Vietnam, respectively. Table 1 presents a summary of papers focusing on the behavior of users/potential users of CL. 
Table 1 Papers Focusing on CL Behavior

\begin{tabular}{|c|c|c|c|c|}
\hline Paper & Most Important Attributes & Sample & $\begin{array}{c}\text { Data } \\
\text { Collection }\end{array}$ & Model \\
\hline Frehe et al. (2017) & Trust, usability, publicity & $\begin{array}{c}5 \text { logistics } \\
\text { experts* }\end{array}$ & $\begin{array}{c}\text { Expert } \\
\text { interviews }\end{array}$ & \\
\hline $\begin{array}{c}\text { Le \& Ukkusuri } \\
\text { (2018) }\end{array}$ & $\begin{array}{c}\text { Whether package arrives in } \\
\text { good condition }(85 \%) ; \\
\text { whether delivery is on time } \\
\text { (67\% USA; } 46 \% \text { Vietnam) }\end{array}$ & $\begin{array}{l}549 \text { U.S. } \\
\text { respondents; } \\
509 \text { in } \\
\text { Vietnam } \\
\end{array}$ & $\begin{array}{l}\text { Stated } \\
\text { preference } \\
\text { survey }\end{array}$ & $\begin{array}{c}\text { Descriptive } \\
\text { analysis }\end{array}$ \\
\hline Punel et al. (2018) & Flexibility & $\begin{array}{l}800 \text { U.S. } \\
\text { respondents }\end{array}$ & $\begin{array}{l}\text { Stated } \\
\text { preference } \\
\text { survey }\end{array}$ & $\begin{array}{c}\text { Binary logit } \\
\text { model; Biva } \\
\text { riate logit } \\
\text { model }\end{array}$ \\
\hline $\begin{array}{l}\text { Stathopoulos \& } \\
\text { Punel (2016) }\end{array}$ & Cost, speed & $\begin{array}{c}531 \text { U.S. } \\
\text { respondents }\end{array}$ & $\begin{array}{c}\text { Stated } \\
\text { preference } \\
\text { survey }\end{array}$ & ECRPL** \\
\hline
\end{tabular}

Note. *Five experts include a CL company founder, innovation expert, senior innovation manager, CEO, and technical director.

$* * \mathrm{ECRPL}=$ Error component random parameter logit model.

\section{METHODOLOGY}

\subsection{Stated Preference Choice Modelling}

We conducted a stated preference survey to examine aspects of CL in Qatar. Attributes included in the survey were drawn from the preceding literature review. Crowd shipping is not currently available in Qatar; therefore, in addition to a literature review of surveys in other countries, we made assumptions when choosing attributes. These assumptions were inspired by other traditional shipping smartphone applications. In this context, 'traditional' means that the shipper/driver is employed by the service provider (i.e., the application). Attributes included in our stated preference survey appear in Table 2.

Table 2 Stated Preference Attributes and Levels

\begin{tabular}{|c|c|c|c|}
\hline Attribute & Level 1 & Level 2 & Level 3 \\
\hline Flexibility & $\begin{array}{c}\text { Pickup available } \\
\text { anytime and } \\
\text { anywhere (GPS) }\end{array}$ & $\begin{array}{c}\text { Pickup available } \\
\text { anytime and anywhere } \\
\text { (without GPS) }\end{array}$ & $\begin{array}{c}\text { Home or office } \\
\text { delivery during typical } \\
\text { working hours }\end{array}$ \\
\hline Delivery Person's Profile & $\begin{array}{c}\text { Transparent; } \\
\text { includes rating, } \\
\text { age, and gender }\end{array}$ & $\begin{array}{c}\text { Anonymous, with; } \\
\text { rating only }\end{array}$ & \\
\hline Insurance & Yes & No & Within 30 minutes \\
\hline Delivery Accuracy & On time & Within 15 minutes & 20 QR \\
\hline Cost & $5 \mathrm{QR}$ & $10 \mathrm{QR}$ & \\
\hline
\end{tabular}

Random service provider profiles were created, representing all possible combinations of each attribute level. In total, 108 profiles were generated $(3 \times 2 \times 2 \times 3 \times 3=108)$. Each respondent was presented with three profile options per question and asked to choose their preferred version. Respondents were then presented with 15 random questions out of 36 possible questions. This random design technique is robust because, in this case, each respondent was exposed to random profiles (Rusch, 2015). The survey 
was divided into three sections. The first placed respondents in a scenario in which they were required to use a crowd-shipping app. As such apps are not currently available in Qatar, the app structure was developed based on Le, Stathopoulos, Van Woensel, and Ukkusuri's (2019) model. According to this model, the customer decides to use a CS crowd-shipping app. Then, based on certain attributes (e.g., price and rating), the requester chooses an offer. The app in this case is only a platform to determine pricing and routing. Generally, crowd-shipping drivers in CS are classified into three types: (1) traditional professional carriers (e.g., DHL and FedEx); (2) professional drivers who participate in crowd shipping in their free time; and (3) occasional drivers who have no professional shipping experience (Le et al., 2019). An important assumption in this survey was that the driver is an occasional rather than professional driver. This assumption was intended to help familiarize respondents with the crowd-shipping model. When designing the pilot survey, interviews were conducted with three pilot respondents to ensure potential participants would understand the scenario well. The second survey section included demographic items (e.g., respondents' gender and age). The third section presented the stated preference service provider options discussed earlier; a sample question is shown in Figure 1.

\begin{tabular}{|c|c|c|c|}
\hline \multicolumn{4}{|c|}{ Choose one option. } \\
\hline $\begin{array}{c}\text { Delivery Place/ } \\
\text { Time }\end{array}$ & $\begin{array}{c}\text { Anyplace/ anytime } \\
\text { pickup (GPS-track) }\end{array}$ & $\begin{array}{c}\text { Anyplace/ anytime } \\
\text { pickup (no GPS) }\end{array}$ & $\begin{array}{c}\text { Anyplace/ anytime } \\
\text { pickup (no GPS) }\end{array}$ \\
\hline $\begin{array}{c}\text { Driver Profile } \\
\text { Visible, with rating, age } \\
\text { and gender }\end{array}$ & $\begin{array}{c}\text { Anonymous, with } \\
\text { rating only }\end{array}$ & $\begin{array}{c}\text { Anonymous, with } \\
\text { rating only }\end{array}$ \\
\hline $\begin{array}{c}\text { Package } \\
\text { Insurance }\end{array}$ & Yes & Yes & No \\
\hline $\begin{array}{c}\text { Delivery Time } \\
\text { Accuracy } \\
\text { Cost }\end{array}$ & Within 30 minutes & Within 15 minutes & Within 15 minutes \\
\hline Option 1 & 20 QR & 5 QR & 10 QR \\
\hline \hline Option 2 & & & \\
\hline \hline Option 3 & & & \\
\hline
\end{tabular}

Figure 1: Sample Survey Question

\subsection{Target Population}

The target population for this survey consisted of individuals older than 18 who were living in Qatar. The country is home to two distinct groups: a Qatari and nonQatari population. The latter group exhibits an unbalanced demographic structure with uneven gender distribution (Planning and Statistics Authority in Qatar, 2018). In 2018, the country hosted 361 female expats for every 100 male expats. This distribution led women to be underrepresented in the survey (39.9\% of respondents). However, a U.S. survey indicated that men are $150 \%$ more likely than women to use crowd-shipping services (Punel et al., 2018).

\subsection{Data Collection}

The survey was conducted between July 2019 and October 2019 via www. surveyanyplace.com. The survey link was distributed by email, social media, and link flayers on Hamad Bin Khalifa University campus. Of 381 initial respondents, 280 completed the entire survey. The average completion time was approximately 4 mins (3:57). The 280 responses were sorted in descending order based on completion time. An mlogit model was estimated with an intercept to display preferences for each question's 
position. We did not expect respondents to choose an answer based on where it appeared in the option table (i.e., in the top, center, or bottom row). The model revealed that the position of each response option was significant for all responses. Therefore, the responses with the fastest completion time were discarded until 145 responses remained, at which point the position became insignificant (Table 3); each position coefficient demonstrated a high p-value.

Table 3 Preference Estimates by Survey Question Position

\begin{tabular}{|c|c|c|c|c|}
\hline Position & Estimate & Std. Error & $\boldsymbol{z}$-value & $\operatorname{Pr}(>|\mathbf{z}|)$ \\
\hline pos 2:(center) & 0.0279912 & 0.0666221 & 0.4201 & 0.6743772 \\
\hline pos 3:(bottom) & -0.1023388 & 0.0641355 & -1.5957 & 0.1105633 \\
\hline
\end{tabular}

\section{RESULTS}

This section presents a detailed overview of our survey results. The mlogit package in R software was used to simulate a multinomial regression model to estimate the likely importance of each attribute (Croissant, 2003).

\subsection{Descriptive Analysis}

Survey results indicated that $57 \%$ of male respondents and $54 \%$ of female respondents would be willing to work as crowd shippers for a specific amount of money, as listed in Table 4.

Table 4 Respondents' Willingness to Work (Persons)

\begin{tabular}{|c|c|c|c|c|c|c|c|}
\hline \multirow{2}{*}{ Age Group } & \multicolumn{2}{|c|}{ Not Willing to Work } & \multirow{2}{*}{ Total } & \multicolumn{2}{|c|}{ Willing to Work } & Total & \multirow{2}{*}{ Grand Total } \\
\cline { 2 - 3 } \cline { 5 - 6 } & Female & Male & & Female & Male & & \\
\hline $18-24$ & 9 & 6 & 15 & 5 & 5 & 10 & 25 \\
\hline $25-34$ & 13 & 22 & 35 & 14 & 23 & 37 & 72 \\
\hline $35-44$ & 4 & 10 & 14 & 11 & 19 & 30 & 44 \\
\hline $45-54$ & & & & 1 & 3 & 4 & 4 \\
\hline Grand Total & $\mathbf{2 6}$ & $\mathbf{3 8}$ & $\mathbf{6 4}$ & $\mathbf{3 1}$ & $\mathbf{5 0}$ & $\mathbf{8 1}$ & $\mathbf{1 4 5}$ \\
\hline
\end{tabular}

Respondents' reported incentives to work are listed in Table 5. Of the 81 respondents willing to work, most were interested in earning money. Men were especially interested in supporting the environment, whereas women desired a sense of community.

Table 5 Respondents' Motivations to Work

\begin{tabular}{|c|c|c|c|}
\hline Gender & Earn Money & Support the Environment & Sense of Community \\
\hline Male & $96 \%$ & $30 \%$ & $20 \%$ \\
\hline Female & $87 \%$ & $26 \%$ & $29 \%$ \\
\hline
\end{tabular}

Note. Some respondents cited more than one reason.

In terms of hypothetical work schedules, slightly more than half $(56 \%)$ of respondents stated they would work weekly, 19\% monthly, and 26\% daily.

\subsection{Choice Modelling}

Survey findings are based on 2,175 different choice tasks. The part worth values in Table 6 represent the mean value of each level (Rusch, 2015). 
Table 6 Part Worth for Each Attribute

\begin{tabular}{|c|c|c|c|c|}
\hline Attribute & Estimate & Std. Error & $\boldsymbol{z}$-value & $\operatorname{Pr}(>|\mathbf{z}|)$ \\
\hline Having insurance & 0.958545 & 0.069602 & 13.7718 & $<2.2 \mathrm{e}-16$ \\
\hline Anyplace/anytime pickup (No GPS) & -0.588422 & 0.069718 & -8.44 & $<2.2 \mathrm{e}-16$ \\
\hline Transparent delivery person profile & 0.559581 & 0.054644 & 10.2405 & $<2.2 \mathrm{e}-16$ \\
\hline Home/office pickup during working hours & -0.444719 & 0.067474 & -6.591 & $4.37 \mathrm{E}-11$ \\
\hline Delivery within 30 minutes of scheduled time & -0.278106 & 0.068523 & -4.0586 & $4.94 \mathrm{E}-05$ \\
\hline Cost & -0.069051 & 0.004745 & -14.5522 & $<2.2 \mathrm{e}-16$ \\
\hline Exact time delivery & 0.062655 & 0.078187 & 0.8014 & 0.4229 \\
\hline
\end{tabular}

Log likelihood coefficients are shown in Table 6; attributes not listed in the table are base attributes. Estimates are on a logit scale between -2 and 2, where a higher magnitude indicates that the attribute is more important, and a negative sign indicates that the opposing attribute is more important. All estimates were statistically significant $(p>0.05)$ apart from 'exact time delivery'. Standard values for all attributes were low. Based on these findings, having insurance was reportedly the most important attribute, which is in line with the findings of Le and Ukkusuri (2018). The second most important attribute was 'anytime and anyplace delivery (with GPS)', which allows for greater flexibility according to Punel et al. (2018). Respondents favored a transparent delivery person profile, apparently due to trust concerns as suggested by Frehe et al. (2017). Respondents did not appear to mind a 15-min. delivery delay. Cost was not an important attribute, which may be associated with customers' trust concerns: the hypothetical delivery person was occasional and not employed by the delivery app company, and respondents were willing to pay more.

\subsection{Willingness to Pay}

Consumers' willingness to pay (WTP) suggested that on average, customers would be equally divided between crowd-shipping attributes at a given price; that is, the price in Qatari Riyal (Table 7) represents the price at which customers appeared indifferent to corresponding attributes.

Table 7 Willingness-to-pay Values

\begin{tabular}{|c|c|}
\hline Attribute & WTP in QR \\
\hline Having insurance & 13.8 \\
\hline Having GPS tracking and flexible delivery place & 8.5 \\
\hline Transparent delivery person profile & 8.1 \\
\hline
\end{tabular}

\section{CONCLUSION}

Policymakers and businesses can benefit from this study because it delineates initial key factors of Qatar's CL business model. Findings reveal how potential consumers may react to crowd-shipping attributes, how much they would be willing to pay for such a service, and whether they would be willing to work as crowd shippers. The implementation of $\mathrm{CL}$ is expected to benefit the environment by reducing road traffic. However, additional research should be conducted using more complex survey techniques, such as an adaptive-conjoint survey. A larger pool of responses would also 
result in greater confidence in each attribute. Scholars can use the present findings as a starting point to further explore CL implementation in Qatar. Notably, combining the most important attributes into one business model might not be practical given high associated costs. It is essential to simulate share predictions in a model with a higher number of respondents and without unrealistic profiles. Policymakers may benefit from this research by realizing that introducing the CL model in Qatar will present trust complexities; governmental regulation of CL may effectively reduce consumers' lack of trust.

\section{REFERENCES}

Akyelken, N. (2011). Green logistics: Improving the environmental sustainability of logistics. Transport Reviews, 31(4), 547-548. https://doi.org/10.1080/01441647.2010.537101.

Brabham, D. C. (2013). 1 concepts, Theories, and cases of crowdsourcing. In Crowdsourcing (p. 168). https://doi.org/10.7551/mitpress/9693.003.0005.

Brunner, G., Szebedy, B., Tanner, S. \& Wattenhofer, R. (2018). The urban last mile problem: Autonomous drone delivery to Your balcony. Retrieved from http://arxiv.org/abs/1809.08022.

Buldeo Rai, H., Verlinde, S., Merckx, J. \& Macharis, C. (2017). Crowd logistics: an opportunity for more sustainable urban freight transport?. European Transport Research Review, 9(3), 1-13. https://doi.org/10.1007/s12544-017-0256-6.

Carbone, V., Rouquet, A. \& Roussat, C. (2017a). The rise of crowd logistics: A new way to co-create logistics value. Journal of Business Logistics, 38(4), 238-252. https://doi.org/10.1111/ jbl.12164.

Carbone, V., Rouquet, A. \& Roussat, C. (2017b). The rise of crowd logistics: A new way to co-create logistics value. Journal of Business Logistics, 38(4), 238-252. https://doi.org/10.1111/ jbl.12164.

Castillo, V. E., Bell, J. E., Rose, W. J. \& Rodrigues, A. M. (2018). Crowdsourcing last mile delivery: Strategic implications and future research directions. Journal of Business Logistics, 39(1), 7-25. https://doi.org/10.1111/jbl.12173.

Croissant, Y. (2003). Estimation of multinomial logit models in R: The mlogit Packages An introductory example. Data Management, 73. Retrieved from http://scholar.google. com/scholar?hl=en\&btnG $=$ Search \&q=intitle:Estimation + of + multinomial + logit + models + in $+\mathrm{R}+:+$ The + mlogit + Packages + An+introductory + example $\# 0$

Edwards, J. B., McKinnon, A. C. \& Cullinane, S. L. (2010). Comparative analysis of the carbon footprints of conventional and online retailing: A "last mile" perspective. International Journal of Physical Distribution and Logistics Management, 40(1-2), 103-123. https://doi. org/10.1108/09600031011018055

Frehe, V., Mehmann, J. \& Teuteberg, F. (2017). Understanding and assessing crowd logistics business models - using everyday people for last mile delivery. Journal of Business and Industrial Marketing, 32(1), 75-97. https://doi.org/10.1108/JBIM-10-2015-0182.

Furuhata, M., Dessouky, M., Ordóñez, F., Brunet, M. E., Wang, X. \& Koenig, S. (2013). Ridesharing: The state-of-the-art and future directions. Transportation Research Part B: Methodological, 57, 28-46. https://doi.org/10.1016/j.trb.2013.08.012

Ghajargar, M., Zenezini, G. \& Montanaro, T. (2016). Home delivery services: innovations 
and emerging needs. IFAC-PapersOnLine, 49(12), 1371-1376. https://doi.org/10.1016/j.ifacol.2016.07.755

Goetting, E. \& Handover, W. N. (2016). Crowd-shipping: Is crowd-sourced the secret recipe for delivery in the future? (I).

Le, T. V., Stathopoulos, A., Van Woensel, T. \& Ukkusuri, S. V. (2019). Supply, demand, operations, and management of crowd-shipping services: A review and empirical evidence. Transportation Research Part C: Emerging Technologies, 103(October 2018), 83-103. https://doi. org/10.1016/j.trc.2019.03.023.

Le, T. V. \& Ukkusuri, S. V. (2018). Crowd-shipping services for last mile delivery: analysis from survey data in two countries. (18), 1-23. Retrieved from http://arxiv.org/abs/1810.02856.

Le, T. V. \& Ukkusuri, S. V. (2019). Modeling the willingness to work as crowd-shippers and travel time tolerance in emerging logistics services. Travel Behaviour and Society, 15(February), 123-132. https://doi.org/10.1016/j.tbs.2019.02.001.

Luisa Dos Santos Vieira, C., Sérgio Coelho, A. \& Mendes Luna, M. M. (2013). ICT implementation process model for logistics service providers. Industrial Management \& Data Systems, 113(4), 484-505. https://doi.org/10.1108/02635571311322757.

Odongo, B. (2018). How crowd sourcing is changing the face of last mile delivery: Crowd logistics. (May). Retrieved from https://www.theseus.fi/handle/10024/149856.

Peiling, Z. \& Tingting, L. (2018). Understanding consumer preferences for logistics services within online retailing of fresh products A research conducted on Swedish consumers. Wired Magazine. Retrieved from https://www.wired.com/2006/06/crowds/.

Planning and Statistics Authority in Qatar. (2018). Woman and Man in the State of Qatar, a Statistical Profile. In Qatar, Planning and Statistics Authority in. Retrieved from https://www.psa. gov.qa/en/statistics1/StatisticsSite/Pages/SocialTopics.aspx.

Punel, A., Ermagun, A. \& Stathopoulos, A. (2018). Studying determinants of crowd-shipping use. Travel Behaviour and Society, 12, 30-40. https://doi.org/10.1016/j.tbs.2018.03.005.

Punel, A. \& Stathopoulos, A. (2017). Modeling the acceptability of crowdsourced goods deliveries: Role of context and experience effects. Transportation Research Part E: Logistics and Transportation Review, 105, 18-38. https://doi.org/10.1016/j.tre.2017.06.007.

Rougès, J.-F. \& Montreuil, B. (2014). Crowdsourcing Delivery : New Interconnected Business Models to Reinvent Delivery. $1^{\text {st }}$ International Physical Internet Conference, (1), 1-19.

Rusch, T. (2015). R for marketing research and analytics. In Journal of Statistical Software (Vol. 67). https://doi.org/10.18637/jss.v067.b02.

Savelsbergh, M. \& Van Woensel, T. (2016). City logistics: Challenges and opportunities. Transportation Science, 50(2), 579-590. https://doi.org/10.1287/trsc.2016.0675.

Stathopoulos, A. \& Punel, A. (2016). Modeling People's Behavior and Acceptance of Crowdsipping. Trr.

Uber. (2019). Uber requirements for drivers in Qatar | Uber. Retrieved April 19, 2019, from https://www.uber.com/en-QA/drive/requirements/.

Voss, C., Tsikriktsis, N. \& Frohlich, M. (2002). Case research in operations management. International Journal of Operations \& Production Management, 22(2), 195-219. https://doi. org/10.1108/01443570210414329.

Zellner, M., Massey, D., Shiftan, Y., Levine, J. \& Arquero, M. J. (2016). Overcoming the Last- 
Mile Problem with Transportation and Land-Use Improvements: An Agent-Based Approach. International Journal of Transportation, 4(1), 1-26. https://doi.org/10.14257/ijt.2016.4.1.01. 